\title{
VIDEO GAMES AS AMERICAN POPULAR CULTURE
}

\author{
MarkJ. P. WOLF \\ Concordia University of Wisconsin
}

Video games have moved, possibly surpassing even movies, into a central role in American popular culture in a relatively short time, and today there is increasing evidence that the video game console -to some extent, as much as the personal computer- has emerged as a central media device through which "convergence culture" is taking place. In the world of massively multiplayer online games, new (and very real) economies and cultures have evolved with striking rapidity, while on a very different scale we see casual games like Angry Birds (2009) and Candy Crush (2012) increasingly becoming integrated into the rhythms of everyday life. Perhaps more than any other aspect of popular culture, video games have blurred the distinction between work and play; the games we play (and work at) tell us about American popular culture and where it is going.

Since their appearance as a commercially-available product in 1971, and as a consumer product in 1972, video games have become a major industry in the area of American popular culture. American cultural values have shaped what video games have become, and two of those values, invention and innovation, have expanded the variety of video games so broadly that only a few broad generalizations can now be made regarding the character of American video games. The highly competitive nature of American society has provided fertile ground for competitive gaming, which has become the dominant form of gaming (as opposed to other forms, such as co-operative play, sandbox-style play, puzzle-solving games, and so forth). In the 1970s and 1980s, arcades provided public venues for video game play, and from Star Fire (1980) onward, high-score tables, which allowed players to compare performances, meant that even single-player games had a competitive element to them (players could also compete with their own performances as well). Competition is often involved with the acquisition of goods, property, and position (which, at various levels in American culture, has resulted in consumerism, materialism, and imperialism), and equivalent activities in video games include the collecting of objects or points and the attaining of high scores or higher levels within a game. The fast pace of these games reflects, and contributes to, the pace of American life, which has for the most part accelerated since the 1970s, as technologies like the computer, microwave oven, cell phones, the Internet, and so forth increase the convenience and speed of many of the tasks found in daily life. 
Other aspects of American culture, such as its relative extroversion, inventiveness, pioneer spirit, and appetite for novelty, are also apparent in many of the games developed in the USA, as well as in the way many American game companies are run, with informal, playful atmospheres that nonetheless have busy schedules and long hours. Besides competition and acquisition, other themes such as cross-cultural conflict, cultural assimilation, and the importance of personal identity (found in such games as the Grand Theft Auto series, the cities of which are very American in their depiction and action), are explored in many games. Some games, like Red Dead Redemption (2010) and BioShock Infinite (2012), even have designs which are highly influenced by American history, even when their settings are entirely fictional.

The ways in which video games have affected and been influenced by American popular culture have changed much over the first five decades of their existence, and so a historical approach is useful in exploring the topic, beginning with the cultural context into which video games made their first appearance.

\section{VIDEO GAMES' ENTRANCE INTO POPULAR CULTURE}

Apart from a few early games like Spacewar! (1962) which were experimental in nature and programmed on mainframe computers housed at universities and unavailable to the public, video games entered into popular culture through the venue of the arcade. During the 1950s and 1960s, arcades were places where rows of coin-operated entertainment-based machines could be found, in a traditional dating back to the 1890s and 1900s when mutoscopes, kinetoscopes, trade stimulators, and other coin-operated machines offered short movies, games of chance, and games of skill to patrons for their spare change. During the 1930s and 1940s, pinball games became popular, and shooting games designed like miniature shooting galleries, complete with guns mounted on the game cabinets, also appeared in arcades. By the late 1960s, a wide range of electromechanical coin-operated games offered players several genres of games, including shooting games, racing games, trivia games, themed pinball games, combat games, sports games, and more. Depending on the venue, such games might be played alongside other table-top games like pool, ping-pong, air hockey, and skeeball, some of which also required coins to play.

After the development of integrated circuits and commercial microprocessors, which allowed the miniaturization and standardization, respectively, video games were able to become commercial products, and they entered the arcade and took on the same forms and content that was already found in electromechanical games. Both types of games were housed in upright cabinets which provided a window on the action placed above a board of controls which was positioned at the height where a standing player's hands would be as he or she stood in front of the cabinet, and video games replaced the cabinet interior where the action took place with a television monitor and visuals that were on-screen. The content of most early arcade video games also reflected the genres already found in the arcade, such as shooting games, racing games, sports games, and versions of table-top games, such as the first video game hit, Atari's PONG (1972).

As a technological novelty, video games attracted audiences hungry for new technologies and new experiences, and were a part of the many attempts to combine art and technology that had occurred throughout the 1960s. Movements of minimalist art and electronic music coincided with the appearance of video games, and while they might not have had any direct 
influence on the design of the games, they did provide a context in which the rather simple graphics and sounds of early games would be more acceptable to audiences, though it was the games' interactive nature that made them unique as an experience. From a financial standpoint, video games became attractive to arcade owners and operators, since they proved to be more reliable than electromechanical games in the long run by reducing the number of moving parts necessary, which also reduced the need for frequent repairs and replacement parts. As video games became more sophisticated and were able to offer a greater range of playing possibilities, they began to displace electromechanical games as the arcade's dominant form of gaming, and eventually even pinball games, which would never completely disappear, would begin their decline once video games gained prominence. By the late 1970s and afterwards, arcades would come to be known for video games more than any other type of games, and sometimes even be referred to as "video game arcades".

Video games also claim another reason for cultural significance; for most of the American general public, they would be the first encounter with computer technology on a personal basis. While most large-scale computer technology of the early 1970s was found at universities and businesses, and not available to the public, video games provided access and user-friendly interaction that combined computer technology with fun. Concurrent with arcade video games, home video game systems, beginning with Ralph Baer's Magnavox Odyssey in 1972, brought computer technology into the home for the first time, and gave it a purpose (other tasks that computers would eventually take over were already being done by typewriters, pocket calculators, telephones, and other existing technologies of the day). Home video games of the 1970s and 1980s, then, can be seen as paving the way for home computer technology, which might otherwise had a more difficult time becoming established, due to the initially high prices of home computers along with the fact that there were no other tasks for home computers to do that weren't handled by other technologies. Games, then, provided an impetus for the purchase of home computers, and some, like the T199/4a Texas Instruments home computer, even had a slot for cartridges built into them. Likewise, some video game companies, like Atari and Coleco, also produced lines of home computers along with home game console systems.

Home computers also allowed video games to enter American culture as the products of hobbyists, and the making of games became an activity around which communities of hobbyists would arise. Many of the early home computers, such as the T199/4a, the Commodore VIC-20 and Commodore 64, the TRS-80, and the Apple II, were used for game programming, and magazines of the 1970s and early 1980s, such as Creative Computing (1974-1985), BYTE Magazine (1975-1998), Compute! (1979-1994), 80 Micro (1980-1988), and PC Magazine (1982-2009), promoted it as well. Games provided a reason to learn programming, and magazines often published code that its readers could use, and readers used the magazines to advertise and sell their own games. The existence of home computers made it easier for programmers to enter the video game industry, since they provided a platform that was more accessible than the proprietary home console systems for which specialized programming and cartridge production was required to create games. Some game authors, like Richard Garriott, author of the Ultima series, found success and established their own computer game companies. These kinds of successes, from basement programming to multimillion-dollar companies, served to inspire a whole generation of would-be game programmers, and advanced the hobbyist and homebrew video game scene during the 1980s. 
By 1983, video games were an active and still-growing sector of American popular culture, but with a glut of games on the market, novelty that was wearing off due to audiences expecting still more advances in software and hardware, and cut-throat competition resulting in price slashing and low-quality games, the video game industry faced a crash in North America that ended their golden age and caused some to question whether video games had only been a passing fad. The crash came right after a peak in popularity; in 1981, the home video game market had tripled, and arcade games made an estimated income somewhere between five and seven billion dollars, with 1.5 million arcade video games in operation and around 24,000 arcades across the country. ${ }^{1}$ Even some individual arcade games, like Space Invaders (1978), Pac-Man (1980), and Defender (1980) had each pulled in hundreds of millions of dollars. But warnings heralded a sea change; in October 1981, Atari expected that 10,000 players would take part in its $\$ 50,000$ World Championship event in Chicago, and only about 250 players attended. ${ }^{2}$ And in late 1982, arcade video game profits were lower than expected. Other electronics industries had experienced crashes during the 1970s, including those that produced pocket calculators, digital watches, and CB radios, and even the home video game industry had a crash of its own in 1977; but a rebound followed by five years of success led many to think that another crash was unlikely.

Thanks to video games, the number of arcades more than doubled from 1980 to 1982, but more than 2000 of them would close in 1983. ${ }^{3}$ That year home video game sales dropped, and industry profits were down 35\% from 1982, with industry-wide losses around $\$ 1.5$ billion. ${ }^{4}$ The May 7, 1984 edition of BusinessWeek even featured an article entitled "The Trend is Back to Pinball Machines", convinced the fad was over. Losses forced many small companies to leave the industry; Mattel, whose Intellivision home system made them the third largest player in the industry quit producing games; and even Atari lost over half a billion dollars. The golden age of video games, along with American dominance of the video game industry, had passed into history.

The crash ended in 1985 when a Japan home video game system, released as the Nintendo Famicom (from "Family Computer") in Japan, was renamed the Nintendo Entertainment System (NES) and released in the North American market. Nintendo was more careful about third-party developers than Atari had been, insuring higher quality and family-friendly fare, a strategy that brought success for their system and restored American faith in the video game industry. Around the same time, the producers of American popular culture were also becoming aware of how video games could profitably become a lucrative venue for their commercial franchises.

1 The figure of $\$ 5$ billion for 1981 is found both in Newsweek and Time. See Lynn Langway et al, "Invasion of the Video Creatures", Newsweek, November 16, 1981, pages 90-94, and John Skow, "Games that Play People", Time, January 18, 1982, pages 50-58. But another article, "Arcade games start to flicker", Business Week, December 6, 1982, page 39, claims that "players slid an estimated $\$ 7$ billion worth of quarters into arcade game machines". The figures for arcades and machines in operation come from Play Meter magazine, as mentioned in Steven Kent, The Ultimate History of Video Games: The Story Behind the Craze That Touched Our Lives and Changed the World, Roseville, California: Prima Publishing, 2001, page 152.

2 See Game Informer, May 2005, Volume 15, Number 5, Issue 145, page 150.

3 According to Bernstein Research, as reported in Albert Mehrabian and Warren Wixen, "Lights Out at the Arcade", Psychology Today, December 1983, page 72, and Charles P. Alexander, "Video Games Go Crunch!", Time, October 17, 1983, page 64.

4 From "The Trend is Back to Pinball Machines", BusinessWeek, May 7, 1984, page 37. 


\section{VIDEO GAMES AND OTHER MEDIA}

With the release of Star Wars in 1977, media-based industries, especially the film industry, began to see the value of franchising, as Lucasfilm followed its feature film with a television special, comic books, trading cards, playsets, board games, film sequels, and eventually video games as well. As the home video game industry was taking off after the Atari VCS 2600 popularized cartridge-based systems and invited third-party development of games for its system, an assortment of companies, from Parker Brothers to 20th Century Fox to Quaker Oats, produced cartridges for the Atari 2600, hoping for a hit. Other companies licensed their intellectual property to game-producing companies, resulting in Atari cartridges based on movies, such as Superman (1979), Raiders of the Lost Ark (1981), E.T.: The Extraterrestrial (1982), and Krull (1983), Towering Inferno (1982), and many others. There were also games based on television shows, including Alpha Beam with Ernie (1983), Big Bird's Egg Catch (1983), Cookie Monster Munch (1983), and $M^{\star} A^{\star} S^{\star} H$ (1983) (which was a game based on a television show based on a movie that was based on a book). Some cartridges were even adaptations of television commercials, including Chase the Chuck Wagon (1983) and KoolAid Man (1983), both of which are now sought after by collectors. Other games featured characters who were already transmedia stars, like Rocky and Bullwinkle, Buck Rogers, Bugs Bunny, the Care Bears, the Berenstain Bears, Garfield, the Smurfs, Spider-man, Snoopy, G. I. Joe, Strawberry Shortcake, and Superman.

As of the early 1980s, video game graphics were still rudimentary enough that they strained to represent recognizable characters with small numbers of pixels. Basing these characters on existing franchises and properties gave more depth to the characters and made the game's limited action more meaningful, as players used their imaginations to fill in missing details and situations from other media. During this time, however, video games began to introduce popular characters from their own hits, like Pac-Man, who first appeared in Namco's 1980 arcade game and went on to have his own board game in 1980, a trading card set in 1981, and television cartoon series in 1982 (which ran for two seasons, with a total of 44 episodes), along with plenty of video game sequels, some of which, like Ms. Pac-Man (1981), had their own transmedia merchandise. Later video game stars, like Nintendo's Mario and Luigi, Link from The Legend of Zelda (1986), Lara Croft, and others, would star in series of games and works in other media, like the dreadful The Super Mario Bros. Super TV Show! (1989) that ran for 65 episodes.

As they became a part of popular culture, video games appeared in the background in movies, when characters went to play in arcades, and by the 1980s, they became the central story element of some movies, including Tron (1982), WarGames (1983), Nightmares (1983), Cloak \& Dagger (1984), The Last Starfighter (1984), The Dungeonmaster (1985), The Wizard (1989), Toys (1992), Arcade (1993), and more. Typically in these films, the otherwise virtual activities within video games become tied to real world stakes and consequences, and the development of players' game skills become connected to some type of life-or-death conflict. Several of these movies had video game tie-ins that were planned along with the films themselves, leading to cross-media production and marketing. Games that might have otherwise attracted little notice were attached to well-marketed films, and were positioned for film audiences who wanted to extend their experiences into an interactive form.

By the mid-1990s, the opposite trend began, as films based on video games starting appearing in theaters, including Super Mario Bros. (1993), Double Dragon (1994), Street 
Fighter (1994), Mortal Kombat (1995), Mortal Kombat: Annihilation (1997), Wing Commander (1999), Lara Croft: Tomb Raider (2001), and Final Fantasy: The Spirits Within (2001). Such films underscored the fact that video games were more than simply just an extra venue for transmedia franchises to exploit; they were now a medium of origin for franchises, particularly character-based ones which centered around conflict. Video games and movies both spawned sequels and adaptations of each other, and video games began adapting an increasing number of cinematic conventions as the graphical capabilities of game systems allowed more realistic imagery and action, with cut-scenes that were themselves short movies. At the same time, Hollywood feature films were becoming faster paced and involved an increasing amount of computer graphics as digital effects became more widespread. And this complementarity, in turn, made it easier for franchises to cross over between media, or even be conceived for release in multiple media simultaneously. For example, the video game Enter the Matrix (2003) was released the same month as The Matrix Reloaded (2003), which featured the same characters (played by the same actors) as the film, and a concurrent plotline, with the film and game both making references to each other's story content within their own stories.

Likewise, during the 1990s and 2000s, dozens of television shows appeared, both animation and live-action, which were based on video game characters and worlds. ${ }^{5}$ Over the years, many popular live-action television shows have also featured episodes whose stories revolved around video games, including Star Trek: The Next Generation (1987-1994), Seinfeld (1989-1998), The X-Files (1993-2002), Stargate SG-1 (1997-2007), Futurama (1999-2013), Law \& Order: Special Victims Unit (1999-present), Law \& Order: Criminal Intent (2001-2011), CSI: Miami (2002-2012), and CSI: NY (2004-2013). ${ }^{6}$ The plotlines of these episodes typically involve the consequences of video game play in the real world, or, in the case of science fiction programs, imagined games using advanced technology (usually some form of virtual reality which make the games seem more real than what was currently possible). Video game content has also crossed over into other media, such as comics and board games, and many popular games and game series have their own fan communities on the World Wide Web.

Presently, video games have joined the ranks of other media as a series of venues for which transmedia content is produced, with simultaneous releases in mind, rather than merely adaptation from one medium to another. Even shows and franchises aimed at adults include video games; for example, there are five games based on the Law \& Order franchise, Law \& Order: Dead on the Money (2002), Law \& Order: Double or Nothing (2003), Law \& Order: Justice is Served (2004), Law \& Order: Criminal Intent (2005), and Law \& Order: Legacies (released in seven episodes, 2011-2012), all of which feature the same actors who appear on the television series, with Jerry Orbach, S. Epatha Mekerson, Elizabeth Rohm, Victor Brandt, and Vincent D'Onofrio reprising their roles from the program.

Video games have not only become integrated with other media, but have also expanded into areas of life beyond entertainment, beyond home and arcade, becoming increasingly a part not only of American popular culture, but also American daily life, and it is to these that we next turn.

5 One can find a list of these at http://en.wikipedia.org/wiki/List_of_television_programs_based_on_ video_games.

6 See the section "Non-game series episodes with plots centered on video games" on the Wikipedia page http://en.wikipedia.org/wiki/List_of_television_programs_based_on_video_games. 


\section{OTHER USES FOR VIDEO GAMES}

Even before the age of commercial video games, military flight simulators helped train pilots, and their technology would later be applied to gaming, an early link between skill games and training technologies. When Atari released the arcade game BattleZone (1980), a version known as the Bradley Trainer was commissioned by the U.S. military for tank training. Atari employs did not like working for the military, however, and in the end only two were ever produced. ${ }^{7}$ On-the-job training began experimenting with the use of video games, which could be designed to teach job-related skills, or simulate decision-making situations, with games' real-time interactive making reaction time a factor. Training games became an extension of training videos used by corporations, as on-the-job training became more codified and structured during the 1980s and 1990s, along with the growing integration of computer technology. The use of games for corporate training soon became big business, and by 2008, a study by the Entertainment Software Association (ESA) found that an estimated $70 \%$ of major domestic employers used games for training purposes. ${ }^{8}$ Examples of job training games include Incident Commander (2007) from the U.S. Department of Justice and BreakAway Games, about the coordination of disaster relief efforts; Job of Honor (2007), from The MITRE Company and used for recruiting; and The Cisco Mind Share Game (2009) used for network certification training. A number of companies, such as Minerva Software (formerly Cyberlore) and Marc Prensky's Games2Train, even specialize in developing games for job training, and studies have shown that the interactive learning found in video game training is often more effective than traditional methods. ${ }^{9}$

Job training and business simulations are just a part of the broader use of video games in education, from such early programs as Mario Teaches Typing (1991) to specialized games used in classrooms or in museum displays. Even physical education classes have used video games; Konami's Dance Dance Revolution (1998) was so popular in gym classes that the company released a special "Classroom Edition" of the game with wireless dance mats, which tracked 48 vital metrics including calories burned, and even included lesson plans. ${ }^{10}$ Debates and research regarding the use of video games in education have produced an enormous amount of literature in the last two decades, as different uses of games are implements in classrooms.

The idea of using games for learning was not lost on advertisers, who had managed to introduce advertisements into games beginning in the early 1980s (Atari's Pole Position (1982) used in-game roadside signs to advertise real companies, and Chase the Chuck Wagon (1983), Kool-Aid Man (1983), and Pepsi Invaders (1983), were all essentially advertising). Some came with the products they advertised; Quaker Oats's Cap'n Crunch's Crunchling Adventure (1999) was released on a CD-ROM attached to boxes of cereal. The companies

7 According to Steven L. Kent, The Ultimate History of Video Games: The Story Behind the Craze that Touched Our Lives and Changed the World, New York, New York: Three Rivers Press., 2001, pages 153-155.

8 Steinberg, Scott, "Game Theory: Business Leaders Look to Video Games as the Future of Management Training", Go magazine, March 2010, pages 96-99.

9 Orland, Kyle, "Study: Workers Trained on Video Games Perform Better", Gamasutra, October 19, 2010, available at http://www.gamasutra.com/view/news/31073/Study_Workers_Trained_On_Video_Games_Perform_ Better.php.

10 See http://www.gophersport.com/pe/middle-school-electronic/konami-dancedancerevolutionclassroom-edition. 
most interested in advergaming, as it came to be called, tended to be those marketing food and drink to younger crowd; snack food and soda companies like 7-Up, Coca-Cola, Cheetos, and Pepsi, and fast-food restaurant chains like Burger King, McDonald's, and Domino's Pizza. Advergames could target adults as well; for example, car manufacturers including BMW, Toyota, and Volvo also produced advergames. After the appearance of web-based games, advergames began appearing on-line, usually with links to companies' websites, allowing games to be more closely connected with the company and company information, spreading the games digitally without additional cost, resulting in viral marketing. Services like The Massive Network can insert place ads into on-line video games through the use of software development kits that place advertising images onto in-game billboards, posters, and other surfaces, and can change these ads over time.

As mobile devices came to have better screens and greater storage, they became new venues for games, and allowed the playing of games anywhere the user went. This was a proven strategy, since handheld games had been around since the late 1970s, and handheld console systems since Milton Bradley's Microvision appeared in 1979. Later systems, like Atari Lynx and the Nintendo Game Boy series of systems, popularized handheld gaming in the 1990s, helping the demand for games on mobile devices. The ability to play games anywhere -during commutes on public transportation, between the events of daily life, or even while waiting in line- led to the rise of the casual gaming movement, which involved simple, easy-to-play games which could fill the user's spare minutes and did not require large time investments or feature steep learning curves. These games, like Rovio Entertainment's Angry Birds (2009) or King Digital Entertainment's Candy Crush Saga (2012), are designed for small touch screens and often have brightly-colored graphics and simple gameplay designed to appeal to a broad audience. Often, these games can be downloaded for free, with companies making their money instead from the sale of in-game items. Mobile devices and casual games brought gaming to audiences who previously did not consider themselves game players, easing them into gaming culture.

Social media games also brought legions of new gamers into gaming culture. Games designed to be used on Facebook, like Zynga's Mafia Wars (2008) and Farmville (2009), turn users into players, and many casual games, like Candy Crush Saga, are now Facebook games as well. Such games receive publicity through social media, many even requiring users to help each other, and social media networks help these games to spread quickly and virally, amounting to millions of monthly users. Because social media can be accessed on mobile devices, the overlap between casual games and social media games continues to grow, although the latter depends on a network of multiple users. Although most casual game play done in public serves to isolate users from their surroundings, their faces and gazes aimed at their small, handheld screens, social games offer a connection to other users, though a highly-mediated one with limited interaction available. In a relatively short time, both types of games have embedded themselves deeply in American popular culture and seem to be there to stay.

While one of the stereotypes about video games suggests that they are frivolous or just for fun, the type of games that has come to be known as "serious games" proves that this is not the case. Including the job training games discussed earlier, serious games are specifically designed for uses outside of entertainment; city planning, business simulation, news, education, exercise, art, and so forth. These games have a function and purpose which is usually that of information, education, comment, or criticism, with the game's interaction 
used to engage the audience and make learning more response-driven. Because they involve decisions made by, and feedback from, the user, games can also be used to test users to see whether or not they have learned and integrated the information that a game has presented, and demonstrates that learning and testing can be combined seamlessly together. Advergames, too, can be considered a form of serious games, and since 2003, politicians have been using video games as part of their political campaigns, starting with the game Howard Dean for lowa (2003).

Serious games are one of the fastest-growing areas of video game culture. Advertisers, marketers, and educators have turned the serious games sector into a large industry, recognizing that younger generations who have grown up with video games often respond to them better than to other media outlets involving traditional, noninteractive media. Popular games may even go viral, spreading as word-of-mouth publicity through social media and other electronic channels. The success and rapid growth of serious games in American popular culture is also part of a larger trend toward what has come to be called "gamification".

\section{CONVERGENCE CULTURE AND GAMIFICATION}

Since the appearance of digital technology, especially following the widespread adoption of home computers in the 1980s and 1990s, most analog media technologies have slowly been replaced by their digital equivalents. And these technologies, all based on the computer, have become more alike in the hardware and software they use, resulting in a technological convergence; for example, films are available on DVDs, Blu-ray discs, or by streaming over the Internet, as are television programs, and video games are released on DVDs, Blu-ray discs, and on-line. Likewise, many of the latest home video game console systems can play DVDs, Blu-ray discs, and compact discs (CDs) with audio content, in addition to video games, and they all can access on-line content direct from the Internet. Single-purpose media devices have given way to consoles, tablets, and mobile devices that are able to play a variety of audiovisual content, and content is often designed with transmedial usage in mind, just as the transmedial franchises that provide the content do so in a variety of different media simultaneously.

Video games, then, can be found on mobile phones, every kind of mobile device with a screen, and even on television; one can now find a growing number of channels of Internet television, streamed directly to television monitors with devices like the Roku Streaming Player, which are completely made up of games that are played on the television screen using the television remote as a controller. Any device that features a screen and some kind of input device is likely to have games available for it.

At the same time, there is what is now referred to as the "gamification" of American culture. Culture has always involved play, and play is even older than culture, as theorist Johan Huizinga pointed out long ago. ${ }^{11}$ As mentioned earlier, competition and acquisition have been positioned as goals in American culture, in a variety of ways, and forms of them are ubiquitous enough to make them well-ingrained into people's thinking and worldview. As digital screen technologies have spread, video games have spread as well, and

11 See Johan Huizinga, Homo Ludens: A Study of the Play-Element in Culture, (New York, New York: Routledge, 1949), which analyzed the role and importance of play in culture. 
the attitudes and types of thinking found in gameplay have coincided well with existing attitudes in American culture, making it not just possible but perhaps inevitable that video game structures would come to be applied to a variety of situations in everyday life. Making something into a game can improve user engagement and interest, while competition and the lure of acquisition can provide motivation where little or none may have existed previously, and a gamelike attitude may make something more fun than it would be otherwise, attracting users' attention by turning whatever it touches into entertainment. Gamelike thinking and game mechanics now inform much of the interaction between businesses, individuals, and other institutions, and competition for the individual's attention, time, money, and other kinds of support seems to only encourage gamification itself, especially when its application appears to lead to success.

Gamification has a downside and negative aspects as well; competition can be unfair or unnecessary, and viewing everything in terms of win/loss situations can reduce community feelings and harm interpersonal communication, relationships, and harmony, causing people to rank themselves against others, which can lead to unpleasant results due to both imagined "wins" and "losses". A gamelike attitude may reduce empathy and altruism, as competition promotes a self-centered world-view, and encourages a lack of seriousness where it might otherwise be needed. Taken to an extreme, gamification reduces everything to entertainment, which is then evaluated on the basis of whether or not one has fun playing, at the expense of more important criteria. While one may point out that such criticisms describe situations resulting mostly from excesses or abuses of gamification, rather than the idea of gamification itself, the question of where the line should be drawn between them is still one open to great debate.

Whatever one may think of gamification, its presence and growth demonstrate how video games have become a dominant force within American popular culture, an influence on other media, and a part of everyday life for most Americans. Nor does this impact appear to be lessening; with new technologies on the horizon, including greater screen resolutions, faster processors, better artificial intelligence algorithms and more sophisticated procedural generation techniques, and increasingly immersive user interfaces like the virtual realitybased Oculus Rift, the full impact that video games will have on American culture still remains to be seen. Video games, now appearing in so many forms and configurations that they have surpassed what was previously meant by both terms "video" and "games", are still a growing part of culture, and have begun to steer culture as well, helping to redefine what is popular in American popular culture. 